\title{
Towards a Transdisciplinary Frame: Bridging Domains, a Multidimensional Approach to Information
}

\author{
José María Díaz Nafría*, Francisco Salto Alemany ${ }^{* *}$ \\ *jdian@unileon.es, Science of Information Institute, Washington, U.S.A; Universidad de León, Spain \\ **francisco.salto@unileon.es, Universidad de León, Facultad de Filosofía y Letras, León, Spain
}

\begin{abstract}
A trans-disciplinary frame is proposed, aimed at addressing the very understanding of information in all its variety. It aims at unifying perspectives and integrating techniques from different fields of knowledge and practice, searching for the most overarching account of information phenomena, a better formalization of real processes and a global stance towards problems concerning information. Such research frame might try to answer: Which are the basic distinct accounts of information to be applied in fields from telecommunication to philosophy, from biology to documentation, from logic to quantum physics? Which are the minimum primitive concepts that may cover all of them? Is a unified theory feasible? Could a better information measure be found? Could the societal and practical interest be better preserved in an integrated perspective of information?

The methodological proposal aims at opening a space for the interweaving of different scientific frameworks (characterized by specific paradigms and methodologies) to delve into the very landscape of information, searching for a transdisciplinary treatment of theoretical, technical and practical problems concerning information. It is based on an already active interdisciplinary International community and a critical mass of research groups at the global level. By means of bridging these communities, a new transdisciplinary science of information might emerge as an integrated framework in which information will be considered in all its formal, natural, cognitive, social, technical, ethical and philosophical aspects.
\end{abstract}

Keywords: Science of Information, General Theory of Information, information content, information measure, information ethics, philosophy of information, information technologies

Acknowledgement: The authors wish to express special thanks to the organizers of FIS2010 (Beijin) for their kind invitation and to Mary Jo Deering whose generosity has made possible our participation. We are also grateful to all the participants and contributors in the theme proposal to the European Science Foundation submitted last spring, in which the ideas constituting this article were proposed to vertebrate the new field of science of information.

\section{Striving for a Transdisciplinary Frame on Information}

In contrast with the population in the iron age, who had no chance to understand the nature of iron, we are able in the "information age" to ask ourselves about the very nature of information, setting forth new ways of understanding its content, its measure and its value, as studied and applied in many different scientific, technical and practical contexts. It is said that there are information phenomena in cells, words, antennas, skin, cables, thoughts, electrons, brains, robots, communities, databanks, institutions... Hence talking about information is essentially multidisciplinary. On the one hand, the concept has gained a central role in many disciplines scattering its meaning and establishing gaps among them (Capurro, 2009). On the other hand, a theoretical information approach may bridge apparently irreconcilable disciplines providing solutions to some scientific conundrums (Lyre, 2002). Moreover the scattering effect on information meanings has driven us to the belief that information can be useful for everything, while often it is not enough to cope with our current problems (Brier, 2008). Since we are appealing to the very core of different sciences, a clarification of information phenomena rendering scientific and societal fruits must be multidimensional and trans-disciplinary (Janich, 2008).

Our problems are: Is there a unified understanding of information under all these uses of "information"? How can we simultaneously grant the diversity of information phenomena and the rigour of its theoretical apprehension in a unifying framework? Could a refined concept of information bridge over matter and energy (physics), life (biology), cognition and consciousness (psychology 
and neuroscience) and social systems (sociology)? How can we preserve all practical interests regarding information (from the governing of nature or the implementation of technology to the preservation of social rights, cultural life, human dignity...)?

From the mid 20th century, the endeavour to delve into the nature of information has followed many paths with a certain tendency to be interdisciplinary (for instance, in cybernetics, system theory, cognitive science, aesthetics, etc) but also with a frequently restrictive scope, just only accounting for some aspects of information (syntactic, semantic or pragmatic ones) (Díaz, 2009). While the Mathematical Theory of Information only gave account of the syntactic aspects, many other approaches attempted to give a better account of the multifaceted reality of information. These endeavours developed with a relative independence, obtaining significant achievements in their respective (and somehow separate) fields, but leaving aside an overarching understanding of information.

The state of the art regarding information theories includes distinct ongoing paradigms, such as: complexity (Algorithmic Information Theory, info-computation); entropy vs. order (physics, chemistry); situated (infon theory); intentional (cognitive science, decision theory); semantic (linguistics, communication theory); system (cybernetics); evolution (biology, social theory, etc. Thus, on the one hand, different disciplines presuppose distinct paradigms; on the other hand, the information phenomena that have been addressed by each discipline sometimes overlap, while others leave significant gaps among them (Capurro, 2009; Lyre, 2002; Díaz \& Salto 2009).

In the evolution of the information society, especially since the 1990s, it has become clear that many pragmatic and ethical problems have arisen, indicating that many interests concerning information were left aside by science and technology, or could not be achieved solely by their own means. In order to examine these matters, several groups were constituted, for instance the International Center for Information Ethics (ICIE, 2002), or the Center for Information Policy Research, (CIPR, 2010), to name but a few.

This segregation of scopes is to some extent related to what Brier calls the informational- and the semiotic view, corresponding respectively to bottom-up and top-down approaches. According to the author: "it may be impossible to unite the two paradigms by manipulating basic definitions into unifying compromises" (see fig.1.a). Hofkirchner considers this non-reducible confrontation in terms of the "ways of thinking" such as reductionism and projectionism (Hofkirchner, 2009). He states the problems in terms of the so called Capurro-trilema, which embraces the non-reachable sinonimity among information concepts in different contexts (related to reductionism), the non-sufficiency of analogy (related to projectionism) and the unavoidable equivocity among theories (related to a disjuctivism way of thinking, as for example, that adopted by a hermeneutical approach). This author puts forward a further approach he calls integrationism (see Figure 1.b). This is not so far from what Gregory Bateson considered as a hierarchy of logic types inherent to informational process phenomena, which is also at the core of second order cybernetics (Bateson, 1979).

In the trend of erecting a global understanding of information, several international meetings gathered the most eminent scientists in the field, from quantum physics to humanities: the Conferences on the Foundations of Information Science (celebrated in 1994, 1996, 2002, 2005 -cf. FIS, 2009), the meetings held in Duino, Italy (2007) and León, Spain (2008) (Luhn, Kornwachs, \& Grassmann, 2007; BITrum, 2009). In these gatherings, it was stated that the damaging effects of mixing syntactic and semantic aspects of information have not yet been overcome, and a road must be found which intersects both science and common sense. In other words, the overlapping of the two directions pointed out by Brier (Figure 1.a) has mainly generated confusion in the field. However, an effort can be made to reach mutual understanding in essential aspects. In different stages, the unified view has been outlined - following Hofkirchner's integrationism, cybernetics or the systemic approach - but, as Marijuán has argued, the complexity of theories makes mutual understanding an arduous task that should be carefully examined through what he calls recombination, which - in a more affordable horizon - may "offer a new panoramic view on the sciences themselves and contribute to achieve social adaptability \& sustainability" (Marijuán, 2009). 
a) Top-down and Bottom-up approximation in the foundation of information science (Brier, 2008).

\begin{tabular}{|l|l|}
\hline $\begin{array}{l}\text { Hierarchy of } \\
\text { sciences and arts }\end{array}$ & $\begin{array}{l}\text { View on the foundation of informa- } \\
\text { tion/signification }\end{array}$ \\
\hline Humanities & \\
\hline Social sciences & \\
\hline Psychological sci.
\end{tabular}

b) Ways of thinking, or how identity and difference are thought to relate each other (Hofkirchner, 2009).

\begin{tabular}{|l|l|}
\hline $\begin{array}{l}\text { Ways of think- } \\
\text { ing }\end{array}$ & $\begin{array}{l}\text { Relationship between lower and higher } \\
\text { complexity }\end{array}$ \\
\hline Reductionism & $\begin{array}{l}\text { reduces higher complexity to lower com- } \\
\text { plexity }\end{array}$ \\
\hline Projectionism & $\begin{array}{l}\text { projects higher complexity onto lower } \\
\text { complexity }\end{array}$ \\
\hline Disjunctivism & $\begin{array}{l}\text { disjoins higher complexity from lower } \\
\text { complexity }\end{array}$ \\
\hline Integrationism & $\begin{array}{l}\text { integrates lower complexity into higher } \\
\text { complexity which it differentiates from the } \\
\text { former }\end{array}$ \\
\hline
\end{tabular}

Figure 1: Approaches to integrate diversity of phenomena regarding information

Among the endeavours aimed at providing an overarching account of information in the last decade, it is worth mentioning: Foundations of Information Science (FIS, 2009), the Unified Theory of Information Research Group of Austria (UTI, 2010), the Science of Information Institute of Washington (SCII, 2008) and the BITrum-interdisciplinary research group on information of Spain (BITrum, 2010). The FIS conference of 2010 , held in China, will attempt to articulate a transdisciplinary and trans-national framework for the Science of Information.

In a non-exhaustive survey of relevant communities of information studies, conducted by SCII (2007), over 300 research communities were identified in more than 40 countries. The relative lack of communication and cooperation among communities of information studies has hindered the promotion of a more qualitative and effective approach to information, resulting in a less efficient use of resources which has been a major limitation in solving scientific and societal problems. As concluded in a recent report to the European Commission concerning trust in the information society: the European effort to build an "inclusive, trustworthy, safety, democratic and citizen-friendly Information Society" requires bringing at stage an effective interdisciplinary and international cooperation to address information concerns (RISEPTIS, 2009, Recomm. 1, 2, and 6). This is indeed an international endeavour that cannot be driven considering single-pole values, but instead an intercultural stage, aware of historical, cultural and geographical singularities (Capurro \& Díaz, 2010a; 2010b).

In brief, we reckon to have available the critical mass to erect a transdisciplinary frame on information; we ought to tackle the scientific, technical and societal problems concerning information; this is the occasion to start a global endeavour to erect the frame. To this purpose, we propose 
hereby to open a space for the interweaving of different scientific frameworks (characterised by specific paradigms and methodologies) to delve into the very landscape of information, searching for a transdisciplinary treatment of theoretical, technical and practical problems concerning information. Any approach decided upon to bridge any gap between information concerns might find a place.

\section{What Might Be Pursued?}

Considering the aforementioned limitations of the current approaches to information, we propose for an overarching understanding of information the pursuing of the following objectives:

1. Searching for the most overarching account of information phenomena, by means of a mostly unifying perspective of information through careful levels of abstraction.

2. Searching for better formalisations of real processes (material, biotic, cognitive, communicative, social).

3. Obtaining a global stance toward problems related to information composed of the manifold reflection of the participant frameworks; bringing into a first plane moral issues and social interests.

4. Clarification of the concepts, metaphors, terminology and involved theories, in order to enable a mutual understanding.

5. Setting up an effective interdisciplinary work, creating tools for sharing data on empirical issues, documents on theoretical grounding, and achieving mutual comprehension and criticism.

6. Bringing about new insights into the steering and design of information technologies at personal and social levels.

7. Contributing to the foundations of an effective transdisciplinary science of information driven to consider information in its formal, natural (physical, chemical, biological), cognitive, social, ethical and philosophical aspects by means of a collaborative partaking of specialists in all concerned disciplines.

Relying on the relative maturity of several disciplines, the achievement of these objectives may substantiate in the following results: a) accordance of a general or a set of general theories of information; b) the elaboration of a glossary of concepts, metaphors, theories and problems concerning information, as tool for an alive disambiguation and common understanding of the parties; c) proposal for foundations of a science of information, its problems, solutions and research programme.

\section{A Methodological Proposal for Interweaving the Field}

\subsection{Domains and Frameworks}

Since the very broad nature of information phenomena covers many different aspects of the natural, social and technical world, the research topics can be articulated for the sake of simplicity in a few research domains:

1. Formal aspects of information (mathematical and logical topics)

2. Physical science (physical and chemical topics)

3. Life sciences (biological topics)

4. Cognition and psychology (epistemological, cognition, consciousness and other psychological topics)

5. Information and Communication Technologies (engineering, social and anthropological topics concerning ICT)

6. Social sciences (communication, information society, economical, sustainability topics) 
7. Ethics (ethical, information divide, political and legal topics)

Transversely, several basic frameworks provide a preliminary bridging over research domains. These frameworks pursue, in varying degrees, unity among the diversity of information phenomena. The following list provides a non-exhaustive set of frameworks that might be interwoven in the transdisciplinary research:

- Formal framework: Studies logical and mathematical tools and concepts from main current formal theories, such as channel theory, general information theory and universal logic; pursuing the elaboration of a comprehensive theory which embraces all formal theories of information.

- System Theory framework, around self-organisation from physical structures to complex societies.

- Info-Computational framework, considering information as structure and computation as its dynamics in different systems.

- Philosophical framework, clarifying the very root concepts used in different information domains, contrasting and providing arguments for an elucidation of the informational contents.

- Communicational framework, seeking awareness on the complexity of the processes of significance, communication and interpretation.

- Societal framework, centered in ethical and critical aspects of information and the information society.

- Information Management framework, from the data realm to a sustainable information society (data, information, knowledge management).

- Bio-Informational framework, from molecular complexity to life and cognition. Evolution, genetic information and neural processes. It aims at bridging between the organization of matter, the evolution of life and cognition.

- Quantum-Information framework, from the formality of statistical physics, measurement processes, de-coherence, qbits, and the relation to consciousness. It aims at establishing a strong basis for bridging over physical, life and cognition domains.

\subsection{Interweaving the Field}

The trans-disciplinary research should pursue on the one hand the treatment of all information phenomena, with special care afforded to the most relevant aspects (formal, natural-physical, chemical, biological-cognitive, social, ethical and philosophical), which might also be classified in syntactic, semantic and pragmatic aspects. On the other hand, it should not fall into a single paradigm (as it could, for instance, the systemic one) since none of them is sufficient to tackle all the given problems to which each theoretical framework attempts to provide a solution. We also state the objective of pursuing the global understanding of information, i.e. searching for unity wherever applicable but understanding diversity in its proper level of abstraction. Accounting for the reality of information as a whole, and keeping the utility of each theoretical framework in pragmatic issues (human, social and technical) should constitute the two basic criteria of research for a Science of Information.

To reach these objectives we propose a transversal coordination of: (i) Research domains, defined by their objects of research, and (ii) Frameworks, characterized by the articulation of specific paradigms and methodologies. As it is illustrated, and without attempting to be exhaustive, these study areas correspond to transversal spaces where diverse frameworks may pursue the understanding of the same phenomena and the solution of related problems. As shown in the graph, some approaches concentrate in specific areas, while others embrace a more holistic understanding. While the former provide a maximal concern on specific domains and problems, the latter will allow us to integrate this understanding in a more comprehensive view, therefore, contributing to the aforementioned unification through levels of abstraction. Good communication and mutual 
understanding between parties constitutes a pillar necessary to make this combination of specific and holistic approaches more fruitful.

In order to maintain a cohesive deployment of the programmes, responsibility for domains and for frameworks should guarantee continuity in the treatment of problems and in the development of research programmes respectively. On the other hand, annual meetings for following, discussing and assessing ongoing investigations should be interwoven with virtual meetings for a more continuous monitoring and exchange.

Another fundamental pillar in the development of the research programme is the participation in the development of a glossary for the common consideration of problems, a mutual understanding of each point of view and a clarification of the used concepts, metaphors and terminology. To this purpose, the Glossarium BITri, developed since 2009 by a scientific and edition team of different disciplines and nationalities, coordinated by the authors, may serve as a system or model for a further development (Díaz, Alemany, \& Pérez Montoro, 2010). Finally, contribution to scientific works and dissemination activities will complete the collaborative commitments.

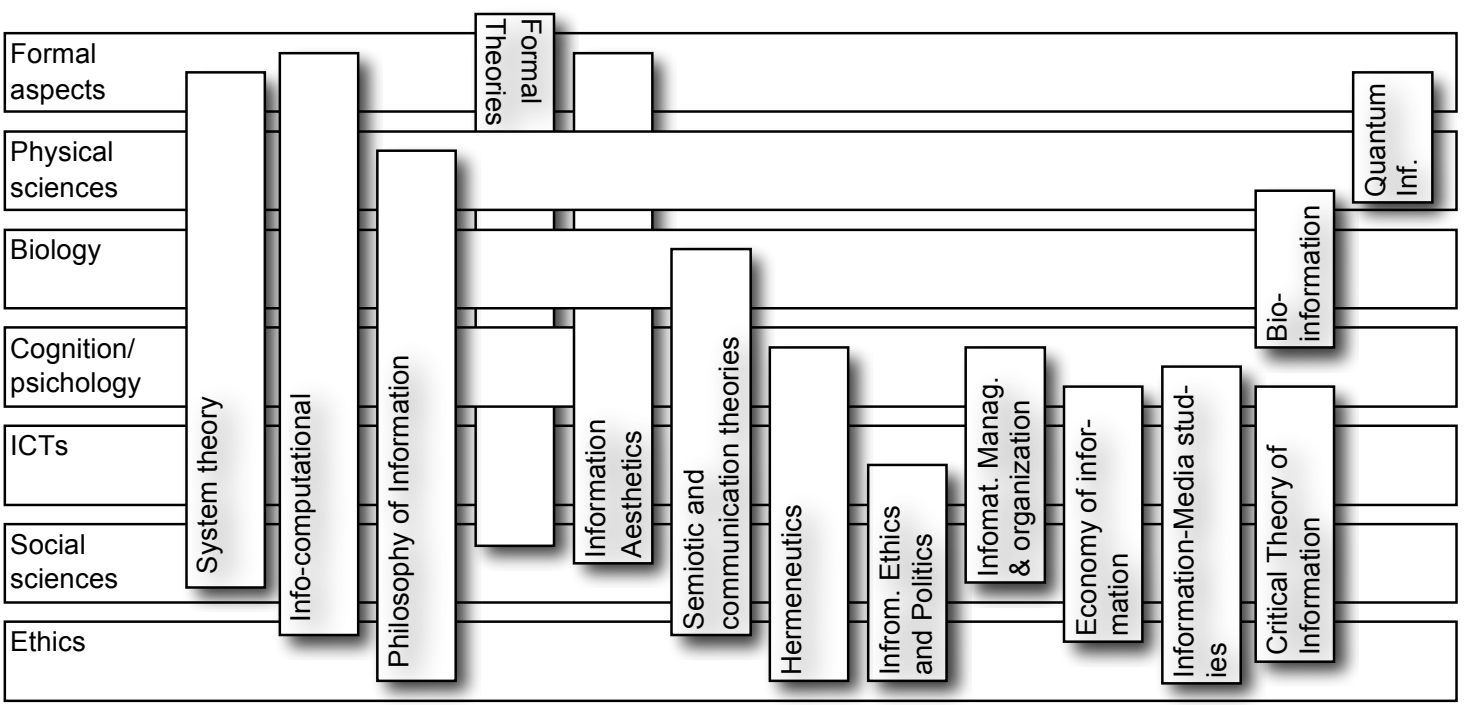

Figure 2: Division of research domains and frameworks of the scientific programme

\section{4. domusBITae: A Virtual Research Community As a Step to Erect a New Science of Information}

The potentials of the target communities (considered as those which make research in any aspect of information, and symbolised as information studies) are represented in tables 1 and 2, corresponding to a non-exhaustive survey driven by the SCII in 2007 and concerning over 300 organizations in more than 40 countries. These potentials -as mentioned above $(\S 1)$ - constitute a major pillar to achieve a significant impact and the synergy required to achieve the objectives for the transdisciplinary research (SCII, 2007). However, these tables also represent the academic (Table 1) and the geographical divide (Table 2) of the scientific community, which hinders an overarching understanding of information.

The domusBITae initiative, aimed at developing a virtual research community in information studies, has been promoted to overcome these divides of the scientific community that in the future might contribute to a fully transdisciplinary Science of Information. This initiative - promoted since 2009 by the authors and a consortium of several institutions of several countries - is aimed at building a virtual research community opened to the participation of any researcher, which will connect the partaking research community around a set of networked resources. Its deployment has al- 
ready begun by means of private and national funds and the request for support submitted to the European Commission (7FP).

\begin{tabular}{lc}
\hline Type of studies & $\mathbf{N}^{\mathbf{0}}$ of communities \\
\hline Artificial Intelligence & 49 \\
\hline Cognitive Science & 38 \\
\hline Communication Science and Media Studies & 27 \\
\hline Computer Science & 51 \\
\hline Cybernetics & 26 \\
\hline Information Science & 36 \\
\hline Information Society Research & 64 \\
\hline Internet Research & 15 \\
\hline Knowledge Studies & 18 \\
\hline Library Science & 16 \\
\hline Philosophy of Information and Infomation Ethics & 20 \\
\hline Research on ICTs & 12 \\
\hline Science of Complexity & 22 \\
\hline Semiotics & 12 \\
\hline Systems Theory & 27 \\
\hline
\end{tabular}

Table 1: Number of communities of Information Studies classified in types (accounted by SCII in 2007)

\begin{tabular}{llllll}
\hline Country & No. & Country & No. & Country & No. \\
\hline Argentina & 1 & France & 3 & Romania & 1 \\
\hline Australia & 7 & Georgia & 1 & Singapore & 1 \\
\hline Austria & 10 & Germany & 25 & Slovakia & 1 \\
\hline Belarus & 1 & Greece & 1 & Slovenia & 3 \\
\hline Belgium & 6 & Hungary & 2 & Spain & 2 \\
\hline Brazil & 1 & Ireland & 3 & Sweden & 8 \\
\hline Bulgaria & 2 & Israel & 1 & Switzerland & 12 \\
\hline Canada & 8 & Italy & 4 & Taiwan & 1 \\
\hline Chile & 1 & Japan & 6 & Thailand & 1 \\
\hline Croatia & 1 & Lithuania & 1 & United Kingdom & 43 \\
\hline Czech Republic & 3 & Netherlands & 4 & U.S.A. & 106 \\
\hline Denmak & 6 & New Zealand & 1 & Venezuela & 1 \\
\hline Estonia & 1 & Norway & 1 & No located & 27 \\
\hline Finland & 4 & Portugal & 1 & Total & 316 \\
\hline
\end{tabular}

Table 2: Number of communities of Information Studies per countries (accounted by SCII in 2007 in a non- exhaustive survey, in which some significant communities were missed as, for instance, the Chinese ones)

The virtual research community in information studies, domusBITae, might be considered as a step in fostering the constitution of a new, unified Science of Information. It pursues bridging horizontally the whole community of information studies in order to (a) share resources and results, (b) improve communication, (c) foster discussion, scientific knowledge \& innovation, (d) disseminate results and (e) promote cooperative research.

As illustrated in Figure 3, domusBITae - according to its current design - will be constituted by the following modules:

1. A knowledge oriented web-system adaptable for any community of information studies, and enabling direct access to both resources of the virtual community and other groups; 
2. A directory of communities which will serve as a bridge between communities;

3. An institutional and thematic repository for Information Studies;

4. A toolkit for working groups to facilitate collaborative research;

5. A shared glossary for conceptual clarification, theory disambiguation, and a multi-faceted approach to informational problems.

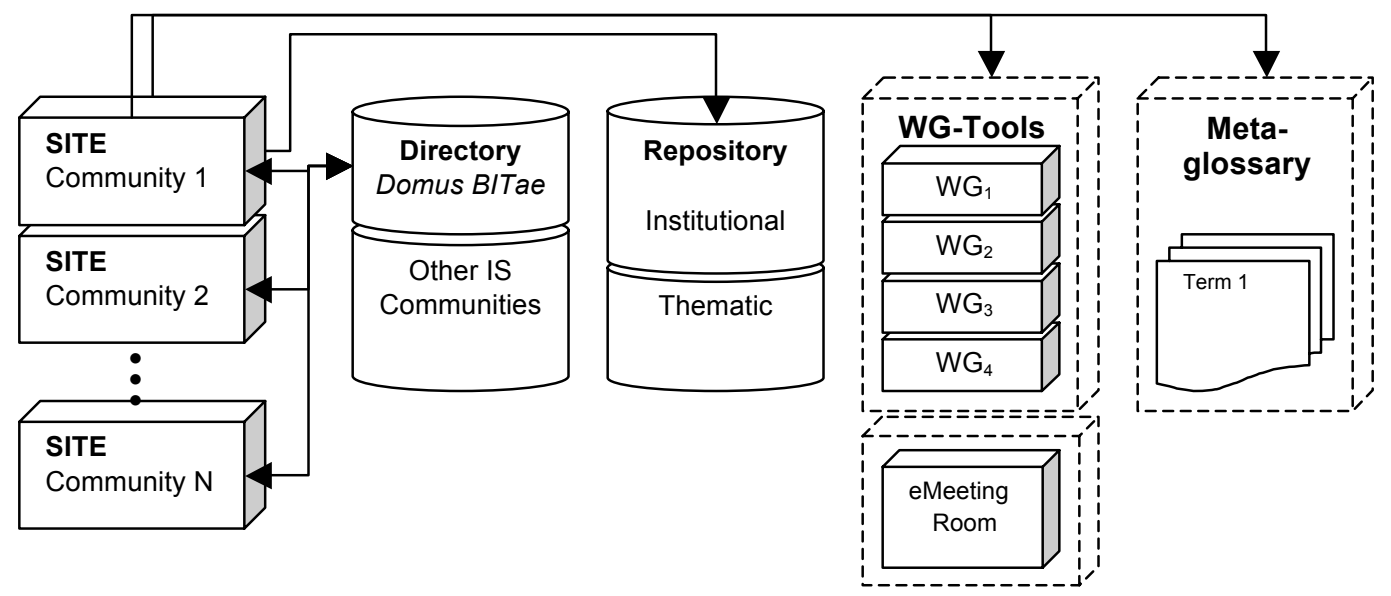

Figure 3: Structure of domusBITae virtual community

\section{Conclusions}

Considering, on the one hand, the relative maturity of the field; on the other hand, the opportunity of erecting a new frame for searching an overarching account of information -based upon ought and resources-: we propose for building a new international research community in information concerns the interweaving of different but collaborative frameworks assisted by a virtual research community (domusBITae), which tools might become a key-factor for an effective mutual understanding, the emergence of synergies and in a mid-term future the constitution of a new Science of Information with solid roots.

\section{References}

Bateson, G. (1979). Mind and nature: A necessary unity. New Jersey, NY: Hampton Press.

BITrum (2009). BITrum: First international meeting of experts in information theory: An interdisciplinary approach. Retrieved from http://en.bitrum.unileon.es/3-activities/gatherings-meetings/first-international-meeting.

BITrum (2010). BITrum. Retrieved from http://en.bitrum.unileon.es.

Brier, S. (2008). Cybersemiotics: Why information is not enough. Toronto, CA: UTP.

Capurro, R. (2009). Past, present, and future of the concept of information. tripleC, 7(2), 125-141.

Capurro, R., \& Díaz Nafría, J. M. (2010a). Information ethics. In Díaz Nafría, J.M., Salto Alemany, F., \& Pérez-Montoro, M. (Coor.). Glossarium BITri: Glossary of concepts, metaphors, theories and problems concerning information (pp. 308314). León, ES: Universidad de León. Retrieved from http://glossarium.bitrum.unileon.es/Home/etica-de-lainformacion/information-ethics.

Capurro, R., \& Díaz Nafría, J. M. (2010b). Intercultural information ethics. In Díaz Nafría, J.M., Salto Alemany, F., \& PérezMontoro, M. (Coor.). Glossarium BITri: Glossary of concepts, metaphors, theories and problems concerning information (pp. 329-336). León, ES: Universidad de León. Retrieved from http://glossarium.bitrum.unileon.es/Home/eticaintercultural-de-la-informacion/intercultural-information-ethics.

CIPR (2010). Center for Information Policy Research. Retrieved from http://www4.uwm.edu/cipr/.

Diaz Nafría, J. M., \& Salto Alemany, F. (Eds.). (2009). Special issue: What is really information? An interdisciplinary approach. tripleC, 7(2), 125-398.

Díaz Nafría, J.M. (2010). What is information? A multidimensional concern. TripleC, 8(1), 77-108. 
Díaz Nafría, J.M., Salto Alemany, F., \& Pérez-Montoro, M. (Coor.). (2010). Glossarium BITri: Glossary of concepts, metaphors, theories and problems concerning information. León, ES: Universidad de León. Retrieved from http://glossarium.bitrum.unileon.es/glossary.

FIS (2009). Foundations of Information Science. Retrieved from http://fis.icts.sbg.ac.at.

Hofkirchner, W. (2009). How to achieve a unified theory of information. tripleC, 7(2), 357-368.

ICIE (2010). International Center for Information Ethics. Retrieved from http://icie.zkm.de.

Janich, P. (2008). Was ist Information? Kritik einer Legende. Frankfurt am Main: Suhrkamp.

Luhn, G., Kornwachs, K., \& Grassmann, H. (2007). Information theory and practice: Workshop programme: Duino 2007. Isomorph. Retrieved from http://www.isomorph.it/science/duino2007/booklet.pdf.

Lyre, H. (2002). Informationstheorie: Eine philosophisch-naturwissenschaftliche Einführung. München: Fink Verlag.

Marijuán, P. (2009). The advancement of information science. tripleC, 7(2), 369-375.

RISEPTIS (2009). Trust in the information society: Report of the Advisory board RISEPTIS (Research and Innovation on Security Privacy and Trustworthiness in the Information Society). Luxembourg: European Commission. Retrieved from http://www.think-trust.eu/riseptis.html.

SCII (2007). Survey on organizations conducting relevant research on the science of information, classified according to their field of research. Retrieved from http://www.soii.info/resources/documents/ScientificCommunities V2.xls.

SCII (2008). Science of Information Institute. Retrieved from www.scii.info.

UTI (2010). Unified Theory of Information Research Group. Retrieved from www.uti.at.

\section{About the Authors}

\section{José María Díaz Nafría}

Obtained a M.Sc. in telecommunication engineering from the Universidad del País Vasco, Bilbao, Spain, and received his $\mathrm{PhD}$ in telecommunication engineering from the Universidad Politécnica de Madrid with a dissertation on "Contributions to the electromagnetic inverse problem". He was also awarded with a M.A. in Philosophy by the Universidad Nacional de Educación a Distancia (UNED). He is currently visiting professor at the University of León, and part of the board of directors of the Science of Information Institute, where he is also scientific advisor. He is co-founder and co-director of the research group BITrum for an Interdisciplinary Elucidation of the Information Concept (http://en.bitrum.unileon.es), as well as members of several international scientific societies in the field of information theories.

He was research fellow at the Vienna University of Technology and at the Technical University of Madrid. He also served as professor at the University Alfonso X el Sabio in Madrid between 1997 and 2009. He has been visiting lecturer at the University of Furtwangen, Sankt Pölten University of Applied Sciences and University of Salzburg. Co-director of the "First International Meeting of Experts in Information Theories" (León, Spain, 2008) and the "Colloquium BITae" (León, Spain, 2009) currently coordinates an interdisciplinary research group meted around the BITrum project (Elucidation of the information concept) and co-edits with F. Salto and M. Pérez-Montoro the Glossarium BITri: glossary of concepts, metaphors, theories and problems concerning information (Universidad de León, 2010) <glossarium.bitrum.unileon.es>, where he authors several articles.

Francisco Salto Alemany

(Graduate in Philosophy and PhD, Universidad de Salamanca, Spain) is Professor of Logic at the Universidad de León (Spain) since 2002, Lecturer at the Institute for Logic, Cognition, Language and Information (University of Basque Country), co-founder and co-director of the research group BITrum for an Interdisciplinary Elucidation of the Information Concept (http://en.bitrum.unileon.es); Fellow and co-founder of the Research Group in Philosophical Logic at the University of Salamanca; Member of the Humanities Group of the University of León, the Unified Theory of Information Research Group (Austria) and is Scientific Advisor of the Science of Information Institute (Washington). He was Assistant Professor at the Universidad de Salamanca, Visiting Fellow at Princeton University and Scholar at the Ruhruniversität Bochum.

His research work in mathematical logic embraces: Logic without Contradiction, Positive Non Classical Negation, Axiomatization, Identity, Games and Game Semantics (developing the software system Ithaca), which has been publicized in different international Journals devoted to Logic. He has also authored several works in philosophy, edited in Theoria, Analecta Husserleana, Phil. Zeitschrift, etc. Dr. Salto co-edits with J.M. Díaz and M. Pérez-Montoro the Glossarium BITri: glossary of concepts, metaphors, theories and problems concerning information (Universidad de León, 2010) <glossarium.bitrum.unileon.es>, where he has authored several articles. 